\title{
Digital educational ecosystem as a tool for the intellectual capital development
}

\author{
Alzhanat Suleimankadieva ${ }^{1,2}$, Maxim Petrov ${ }^{1, *}$, and Andrey Kuznetsov ${ }^{3}$ \\ ${ }^{1}$ Saint-Petersburg State University of Economics (SPbSUE), 21, Sadovaya st., Saint-Petersburg, 191023, Russia \\ ${ }^{2}$ Saint-Petersburg Electrotechnical University («LETI») (SPbETU), 5, Professora Popova st., Saint-Petersburg, 197022, Russia \\ ${ }^{3}$ Udmurt Branch of the Institute of Economics, Ural Branch of the Russian Academy of Sciences, 4, Lomonosova st., Izhevsk, \\ Udmurt Republic, 426000, Russia
}

\begin{abstract}
The analysis of the definitive aspect of the digital ecosystem concept is carried out, a generalized definition of this concept is given, taking into account the specific properties of its existence, which makes it possible to go beyond the IT-contextual understanding. The article provides a comparative analysis of existing approaches to assessing the digital ecosystem of education and forms the author's vision, which expands the content of the assessment mechanism, pays special attention to the impact of the digital education ecosystem on the intellectual capital development. The authors' attention is focused on studying the characteristics of the digital education ecosystem and analyzing the model for the intellectual capital development in the context of the transition of the world and Russian economies to a new technological level. Based on the analysis of empirical data, it is concluded that modern society requires a new structure (construction) and a completely different content of education. Considering the development trends of the world educational space and the characteristics of the modern intellectual economy, the necessity to develop a new model of education as a basic basis for the intellectual capital development is substantiated.
\end{abstract}

\section{Introduction}

The concept of "ecosystem of education" appeared at the beginning of the XXI century and immediately became the subject of public and scientific discussions, despite the fact that in biology the term "ecological system" has existed in scientific discourse for more than eighty years [1]. In biological science, an ecosystem or ecological system (biogeocenosis) is understood as a system consisting of a community of living organisms, their habitat, a system of connections that exchange substances and energy between them [2]. In other words, an ecosystem, as a more general concept, can be represented as a certain set of interrelated and interdependent elements that have general system properties: integrity, emergence, interdependence (connectedness), stability, etc.

Over a period of time spanning more than eight decades, this concept has received sustainable development, both from a theoretical and a practical points of view, confidently and actively being introduced into other branches of scientific knowledge, the field of social and business relations. In the last three decades alone, the concept of an ecosystem has become widespread in such spheres of human activity as: business, economics, finance, banking, manufacturing, education, etc. In this regard, new concepts and terms have appeared, such as: business ecosystem, financial ecosystem; banking ecosystem; an ecosystem for the development of innovations in education; innovation and production ecosystem; digital ecosystem; digital intelligent ecosystem; the ecosystem of the digital economy, the ecosystem of the digital society and the information (digital) ecosystem of the advocacy [3-10], etc. We believe that further analysis of the definitive aspect will lead to a wide variety of types of sectoral ecosystems.

At present, it is difficult to find a scientist-economist who would not admit that the main factor of economic growth and development of modern society is intellectual capital. And only those countries that actively reproduce new knowledge, whose economies are characterized by growing intellectual intensity, will be able to maintain leadership positions in the world economy. Today there is no such area of activity that would not undergo significant changes caused by the active development of technologies of the Fourth Industrial Revolution [11]. These changes are accelerating exponentially. According to K. Schwab and N. Davis [12], the exponential development of society takes place in the second phase of the industrial revolution. The technological changes associated with it form a new system of values that is constantly changing and transforms the existing culture and way of life of

*Corresponding author: petrov_maxim@rambler.ru 
society, the education system through which new knowledge, skills and abilities are transmitted. All this predetermined the relevance of replacing the traditional model of human capital development, based on the transfer of a standard set of highly specialized skills necessary for an employee to perform a separate function and / or a limited group of functions, with a new model focused on the development of flexible skills, and containing the idea of inter- and transdisciplinary learning approaches. Thus, the purpose of this article is to analyze the definitive aspect of the concepts of "digital ecosystem", "digital educational ecosystem" and the formation of a new view (approach) to assess the impact of the digital educational ecosystem on the development of intellectual capital.

\section{Materials and Methods}

The article uses scientific and methodological approaches: 1) theoretical and methodological: content analysis of sources and materials of the Internet network on the problem (study and generalization) of the research; comparative analysis; system analysis and systematization of methods and approaches to assessing the digital ecosystem, including assessing the digital ecosystem of education; structural and functional analysis of the components of the digital education ecosystem that affect intellectual capital; 2) empirical: questionnaire survey (expert assessment); method of statistical processing of data obtained in the course of expert assessment.

The development of the problem under study was carried out on the basis of the study of regulatory documents, monographic studies of Russian and foreign authors, materials of the Internet network, periodicals devoted to the ecosystem approach to the formation of the educational environment as an element (subsystem) of the modern global digital space, which is a «mix» socio-economic and technical (digital environment) system of the public world order. Extrapolation of the research results made it possible to determine the prospects for the development of intellectual capital in the context of technological singularity and sustainable formation of educational ecosystems.

\section{Results and Discussion}

In accordance with the goal set in this article, we are interested in the digital ecosystem in relation to the educational environment, since it has experienced the greatest transformation processes over the past twenty years. Before proceeding to a descriptive analysis of the concept of a digital educational ecosystem, in our opinion, it is advisable to pay attention to a review of the definitions of the concept of "digital ecosystem". Despite the variety of existing definitions of this concept, it can be concluded that there is no unambiguous definition of this term in the literature. However, a common attribute for the formation of digital ecosystems is the use of digital technologies, and, in particular, access to the Internet. For example, in our country, the proportion of organizations using the Internet in their economic activities is steadily growing and it is shown in Figure 1.

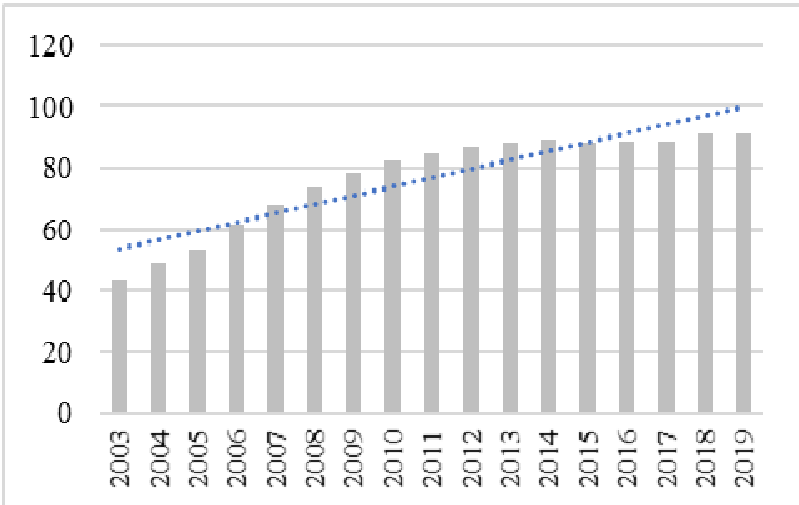

Source: Federal State Statistic Service (Rosstat)

Fig. 1. Share of organizations using the Internet in the Russian Federation, \%

For example, for the purposes of modeling the process of implementation and development of information and communication technologies in 2002, European researchers and practitioners F. Nachira, P. Dini and A. Nikolay proposed the theory of a digital business ecosystem [13]. According to the authors, the digital ecosystem is characterized as a distributed, adaptive, open socio-technical system with the properties of self-organization, scalability, and sustainability. This definition notes that the basis for digital ecosystem models is knowledge about natural ecosystems, including in the field of competition and cooperation between various objects (primarily between enterprises and companies).

Benjamin Talin defines the digital ecosystem as a system focused on creating added value for customers (consumers) by optimizing data and workflows from various internal departments, tools, systems, customers, suppliers and partners. The main characteristics of such an ecosystem are: customer focus (for example, Amazon at first was clearly focused on the customer without an emphasis on monetization, but after a while, it focused on creating value); the ability to collect additional information (data) about customers, transactions, processes, which makes it possible for a global company (ecosystem) to make a more refined offer to its customers; automation of processes, which allows to significantly reduce the costs and prices of products and services; globalization (globality), which allows the ecosystem to scale its offerings, go beyond the terrain, region and country; dynamism, implying a quick response to changes in the environment and adaptation to them, the propensity of business intelligence to make quick decisions [14].

On the other hand, V. Artemiev (CEO of the digital ecosystem All.me) notes that the digital ecosystem can be understood not only as an information technology infrastructure that works on the principle of "win-win" everything, as an infrastructure that can harmoniously and profitably fit into the internal environment of the consumer's economy [15]. Thus, it is possible to generalize the content of the concept of "digital 
ecosystem", without being limited to its essence, defined in relation to the IT-sphere, and give a more comprehensive definition that characterizes it as a sociotechnical system, which has, first of all, system-wide properties (integrity, emergence, interconnectedness and sustainability), and functioning in the context of information and communication technologies, digital technology platforms that allow ecosystem participants to carry out mutually beneficial accumulation, exchange of data (including information and knowledge) in a structured form and management of business processes. This ecosystem works on the basis of the implementation of additional principles: a) algorithmization of the relationships of the participants; b) "win-win" (mutual benefit); c) a unified information and communication infrastructure, which is a digital network structure of participants (agents, actors) and system elements; d) minimization of costs (both material and time) associated with the interaction of ecosystem participants; e) scalability, that is, the ability of the ecosystem to work efficiently and smoothly under conditions of increasing load (for example, with the addition of resources, an increase in the number of network participants, an increase in the volume of work); f) synergistic effect obtained as a result of optimization of business processes (including information exchange and control); g) creating additional value for the ecosystem through a competency model based on the concept of continuous learning (self-development) of the system.

With regard to the educational ecosystem (including the digital educational ecosystem), there are also different views on the acceptability of the ecosystem approach in terms of its formation and content. Thus, some authors (A. Tsvetkova, M. Gustafson) believe that the ecosystem approach, in principle, is not acceptable for the purposes of analyzing the education system [16]. Other authors are actively generalizing and developing the concept of the digital ecosystem in relation to the educational environment. In particular, D.O. Koroleva, T.O. Naushirvanov consider it as an ecosystem for the development of educational innovations [6].

A.M. Kondakov singles out the concept of "digital education ecosystem" and associates its emergence with the intensive growth of the digital economy, which substantiated the feasibility of developing non-specific competencies. This author defines the digital educational ecosystem as a socio-cultural environment in which the process of personalized teaching of students (learners) is based on the analysis of their requests and needs in the interaction of all participants in educational relations using variable, adaptive digital content [17].

According to the autonomous non-profit organization NTI University "20.35", by 2025 the main characteristics of the digital educational environment (ecosystem) should be the following: 1) management of the education system based on Big Data; 2) launching flexible, practice-oriented educational formats; 3) creation and development of methods of transfer and perception of knowledge about technologies "first hand", from technological leaders and experts of Russian and world levels; 4) the formation of a networked educational environment (ecosystem), where there is no border between universities, school and business, but at the same time there is a system of knowledge exchange, which is freely used by both those who teach and those who study; 5) the creation and use of digital tools, with the help of which a person will be able to determine his ability to create relevant educational goals and implement a step-by-step scenario for their achievement [18].

Thus, based on the above definitions of the concept of "digital ecosystem" and "digital educational ecosystem", in our opinion, it is possible to substantiate the main reasons for the emergence and intensive development of the digital ecosystem of education, which will make it possible to give a more precise definition of this term, taking into account its impact on growth and development of intellectual capital. Thus, the analysis of the previously reviewed works allows the authors of this study to note that the main reasons for the creation and development of the ecosystem approach to the educational environment are as follows.

First, the accelerated rate of obsolescence of knowledge has led to an increase in the rate of lag of the education system from the requirements of the real sector (primarily the labor market). In the era of Industry 4.0, the rate of knowledge update is two years. A student who enrolled in a bachelor's program today, after four years (that is, at the stage of completion of the educational process), receives knowledge that has twice become obsolete. The traditional higher education system does not keep pace with the accelerated pace of knowledge change. And this situation testifies to a crisis in the education system (including in the higher education system).

Second, in turn, the crisis of the modern system of (higher) education, associated with the fact that graduates of vocational educational institutions (primarily universities) do not have the necessary professional skills and remain unclaimed in the labor market, justified the expediency of searching for such technologies and approaches to the learning process, transfer of necessary and timely knowledge, which could significantly reduce the "circulation" of knowledge, that is, make the life cycle of the triad "Creation of knowledge - Learning (processing, analysis and transfer of knowledge) - Use of knowledge" very short. This situation requires a new (digital) infrastructure of the education system (including higher education).

Third, the rapid development of the ecosystem approach in relation to the education system is, on the one hand, a reaction to the general digitalization of the economy, and on the other, a consequence of the impact of the COVID-19 pandemic, which accelerated the transformation process at all levels of the educational process and, in fact, accelerated the process of technological singularity in the development of the world economic economy.

Fourth, the digital ecosystem of education can realize itself as a network structure developing on a single technological platform, where each of the participants (agents, actors) has access to common "ecosystem" resources, which he does not have enough or does not have at all. 
Fifth, the digital educational environment (ecosystem) is becoming more and more innovative and project-based, which can be viewed as a synergistic effect of the network structure (the triad "ScienceEducation-Real sector (business environment)") on a single digital platform.

Sixth, the technological revolution in the educational process is actively and intensively converting all communications of the educational system into digital ones. An example is the intense growth of the EdTech segment (Fig. 2). Thus, the forecast of the annual growth rates of this segment in Russia in the next 5 years is about $20-25 \%$ [19].

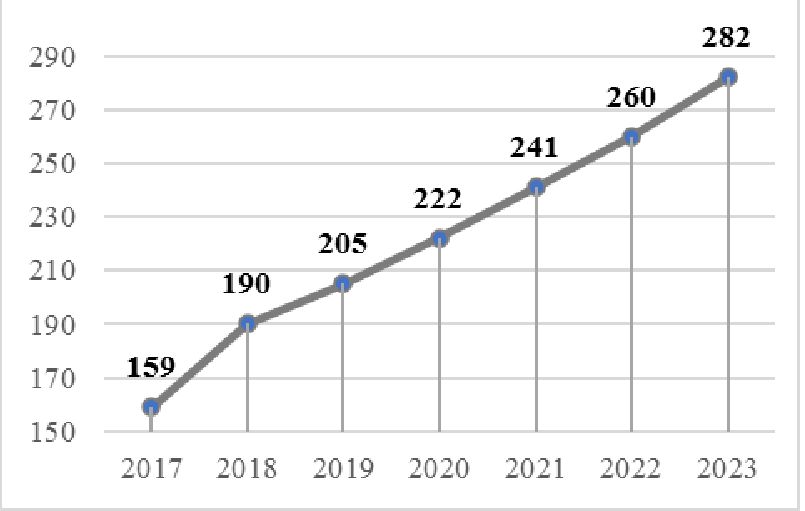

Source: EdTechXGlobal, Global Market Insights, Education International

Fig. 2. Market size of online education, USD billion.

In accordance with the national project of the Russian Federation "Education 2019-2024", the Federal project "Digital educational environment" is focused on the creation and implementation of a digital educational environment in educational institutions, as well as ensuring the implementation of digital transformation of the education system. Within the framework of this project, work is underway to equip organizations with modern equipment and develop digital services and content for educational activities, for the implementation of which a budget of 73.4 billion rubles has been allocated [20].

The main directions of the National Program "Digital Economy" are six federal projects (Table 1) [21].

Thus, a comparative analysis of definitions, characteristics, as well as the main directions of development of the modern education system allows us to note that its main and specific characteristics is the inclusion of digital technologies and platforms in all its areas of activity, that is, new forms and methods of generating, accumulating, storing, analysis, processing, contextualization and control of knowledge, which significantly reduce material and time costs, make knowledge more accessible (cheap) and easily updated. Consequently, the educational ecosystem must be understood not just as a platform on which the process of transmitting knowledge to students takes place, but the processes of generating, analyzing and processing knowledge would be taken outside the educational system. In the modern context, the digital educational ecosystem must be understood as a set of closely and intensively interacting stakeholders (agents, actors), which: a) includes an educational platform, teachers (developers and lecturers), students (students), educational and methodological materials, employers (business - environment), creators of new knowledge (research organizations, laboratories, etc.); b) organizes and carries out its activities either with the participation of only digital technologies, or on the basis of their preferential use; c) accelerates the process of generating intellectual capital and significantly increases the market capitalization of both the education system itself and the digital network structure.

In the methodology of intellectual capital management, there is a wide variety of approaches and methods for assessing intellectual capital, which can be conditionally grouped as follows: 1) quantitative approaches and methods; 2) qualitative and 3) structural approach [22]. The most widespread and actively used approach to assessing intellectual capital is a structural one, which allows a comprehensive assessment of intellectual capital and has a number of advantages, but this approach has its drawbacks. In general, the approach is attractive from the point of view of the possibility of aggregating various indicators, but the assessment mechanism does not allow focusing on the impact of the digital environment (digital component) on intellectual capital, although this approach "covertly" involves digital technologies as part of the information type of capital, which is part of the entire complex index of intellectual capital (along with human, organizational and client types of capital). It should be noted that the structural approach focuses on the building blocks and factors of a composite measure of intellectual capital, but not on technology.

At the same time, in new studies, various methods and approaches to assessing the digital educational space appear, but mainly they relate to the assessment of either the digital economy or the digital innovative educational ecosystem, but do not relate to the impact of the educational ecosystem on the growth of its intellectual capital, the growth of market value. educational ecosystem. In particular, in [6] D.O. Korolev and T.O. Naushirvanov analyze the availability and quality of digital education for the development of innovative educational projects. The assessment is carried out for six types of infrastructure, such as: 1) development infrastructure; 2) legal infrastructure; 3) telecommunication; 4) physical; 5) financial; 6) infrastructure of human resources (personnel). All types of infrastructure are assessed according to two criteria: "availability" and "quality" of digital education. As a result of the study, the authors revealed that the vast majority of innovators (who took part in the study as respondents), according to both criteria ("accessibility" and "quality"), the highest level of digital education in the communication infrastructure (93 and 63\% of participants, respectively). The lowest score was found on the criterion "affordability" for financial infrastructure (only $25 \%$ of respondents gave a positive assessment), but according to the criterion "quality", the level of digital education in legal and physical types of infrastructure turned out to be the lowest (only 21 and 
$28 \%$ of respondents, respectively, noted a high level of education). The sample included representatives of innovative structures from 56 regions of Russia, of which $60 \%$ of respondents were residents of large cities with a population of more than 500 thousand. human.

Table 1. Federal projects of the Russian Federation "Digital Economy" national program

\begin{tabular}{|c|c|}
\hline $\begin{array}{c}\text { Main } \\
\text { directions }\end{array}$ & Project content \\
\hline $\begin{array}{l}\text { Personnel for } \\
\text { the digital } \\
\text { economy }\end{array}$ & $\begin{array}{l}\text { Improving the education system in order } \\
\text { to provide the digital economy with } \\
\text { competent personnel. Transformation of } \\
\text { the labor market, which should be based } \\
\text { on the requirements of the digital } \\
\text { economy. Creation of a motivation } \\
\text { system for the development of the } \\
\text { necessary competencies and the } \\
\text { participation of personnel in the } \\
\text { development of the digital economy of } \\
\text { Russia }\end{array}$ \\
\hline $\begin{array}{l}\text { Information } \\
\text { infrastructure }\end{array}$ & $\begin{array}{l}\text { Creation of the necessary } \\
\text { telecommunication infrastructure and } \\
\text { conditions to achieve the following tasks: } \\
\text { provision of broadband Internet access to } \\
\text { socially significant objects, as well as } \\
\text { effective and safe use of online services } \\
\text { by them; ensuring the possibility of } \\
\text { broadband access to the Internet for } \\
\text { households in sparsely populated, remote } \\
\text { and hard-to-reach settlements; } \\
\text { implementation of modern } \\
\text { communication standards 5G / IMT-2020 }\end{array}$ \\
\hline $\begin{array}{l}\text { Information } \\
\text { security }\end{array}$ & $\begin{array}{l}\text { Achieving a state of protection of the } \\
\text { individual, society and the state from } \\
\text { internal and external information threats, } \\
\text { which ensures the implementation of } \\
\text { constitutional rights and freedoms of man } \\
\text { and citizen, a decent quality and standard } \\
\text { of living of citizens, sovereignty and } \\
\text { sustainable socio-economic development } \\
\text { of the Russian Federation }\end{array}$ \\
\hline $\begin{array}{l}\text { Digital } \\
\text { technologies }\end{array}$ & $\begin{array}{l}\text { Development of promising high-tech } \\
\text { areas, support of domestic companies- } \\
\text { leaders of the information technology } \\
\text { market, as well as stimulating demand for } \\
\text { their solutions, creating conditions for the } \\
\text { development of start-ups that develop } \\
\text { solutions in the field of information } \\
\text { technology in order to ensure national } \\
\text { security, technological independence and } \\
\text { competitiveness at the global level }\end{array}$ \\
\hline $\begin{array}{l}\text { Legal } \\
\text { regulation }\end{array}$ & $\begin{array}{l}\text { Formation of a new regulatory } \\
\text { environment that provides a favorable } \\
\text { legal regime for the emergence and } \\
\text { development of modern technologies, as } \\
\text { well as for the implementation of } \\
\text { economic activities related to their use }\end{array}$ \\
\hline $\begin{array}{l}\text { Digital public } \\
\text { administration }\end{array}$ & $\begin{array}{l}\text { Implementation of digital technologies } \\
\text { and platform solutions in the areas of } \\
\text { public administration and provision of } \\
\text { public services, including in the interests } \\
\text { of the population and small and medium- } \\
\text { sized businesses, including individual } \\
\text { entrepreneurs }\end{array}$ \\
\hline
\end{tabular}

Undoubtedly, such an assessment allows one to get a certain picture of the digital educational space in terms of the availability of knowledge and the quality of its transmission (training), but in order to understand which elements of the digital educational ecosystem have the greatest impact on intellectual capital, other emphasis is needed in the study.

First of all, it is necessary to substantiate whether digital technologies affect intellectual capital, although it is obvious to any user that they have an unambiguous effect? But, on the other hand, it is advisable to highlight the main factors of the digital educational space, which are the main drivers of intellectual capital.

The authors of this work carried out an expert analysis of the elements of the digital infrastructure of the educational ecosystem that affect its intellectual capital and obtained the following assessment results, which are shown in Table 2. The analysis was carried out according to the following criteria:

1. Digital technology platform allows us to implement the following opportunities for digital education: accumulation, storage, processing and analysis, broadcast (training) and control of knowledge (placement and control of work performed, etc.); integration of all processes and types of educational activities (including lectures and practical classes, assessment work (for example, the organization of electronic testing in the process of monitoring students' knowledge, etc.); online organization of round tables, guest lectures, master classes, consultations, video conferences on various technological platforms and systems (for example, ZOOM, BigBlueButton (BBB), Microsoft Teams, Skype, WhatsApp, etc.); continuous replenishment of unlimited educational and methodological literature, including previously recorded lectures (videos, open online MOOC courses); access to library resources and databases, to third-party information resources and sources.

2. Educational and methodological complex of the discipline in digital infrastructure. There is an opportunity for the creation and unlimited improvement of the educational and methodological complex of the discipline in the digital environment. The authordeveloper has the ability to create online courses on a digital platform and continuously supplement their teaching materials, which ultimately contributes to the intensive development of approaches, theories (concepts), replenishment of the base of developed problems, practical examples for analysis and cases (situations) for solving ... This form of material presentation simplifies the process of translating the knowledge of students, reduces the costs associated with the personalization of training.

3. Stakeholders of the information network structure of the (digital educational) ecosystem. It is possible to integrate scientific organizations that develop (create) knowledge, the education system (including the higher education system), which processes, analyzes information and broadcasts knowledge to students, and the real sector (business environment), which is actively used (applied) knowledge gained by students in practice. As a result of such interaction of stakeholders on the digital educational platform, a synergistic effect is achieved. 
4. Innovative projects in the digital education ecosystem. The digital educational ecosystem allows both employers and educational organizations (primarily teachers and students) to unite on a single digital educational platform and helps to implement a huge number of innovative projects offered by employers and developers through the efforts of the teaching and student environment. This approach significantly speeds up the process of commercialization of innovative projects.

5. Learners (students, listeners) in the digital educational ecosystem have: a) access to educational materials, library resources; b) the opportunity from anywhere in the world to attend classes, participate in online events, discussions, master classes, guest lectures, consultations, scientific conferences, competitions.

6. Teachers (course and module developers) on the educational platform have: a) access to information technologies and can place their developments and educational materials there (manuals, work programs, assignments, tests, regulatory documents, etc.); b) the opportunity to improve their qualifications using the online platform, take part in scientific conferences, symposia, congresses, etc.

Students and teachers of St. Petersburg State University of Economics (SPbSEU) participated in the survey as respondents. Column 2 of this table presents a point estimate of the degree of influence of each element (factor) of the digital education ecosystem on its intellectual capital, which is built in such a way that the total (final score) of the combined influence of all factors is 100 points. The assessment involves the most significant assessment criteria that have the same weighting coefficients.

Table 2. Influence of the educational ecosystem digital infrastructure elements on intellectual capital (by the example of SPbSEU)

\begin{tabular}{|l|c|}
\hline $\begin{array}{c}\text { Elements of the digital } \\
\text { infrastructure of the educational } \\
\text { ecosystem }\end{array}$ & $\begin{array}{c}\text { Scoring the impact } \\
\text { of an element on the } \\
\text { intellectual capital }\end{array}$ \\
\hline 1 & 2 \\
\hline Digital technology platform & 30 \\
\hline $\begin{array}{l}\text { Educational and methodological } \\
\text { complex of the discipline in digital } \\
\text { infrastructure }\end{array}$ & 15 \\
\hline $\begin{array}{l}\text { Stakeholders of the information } \\
\text { network structure of the (digital } \\
\text { educational) ecosystem }\end{array}$ & 15 \\
\hline $\begin{array}{l}\text { Innovative projects in the digital } \\
\text { education ecosystem }\end{array}$ & 15 \\
\hline $\begin{array}{l}\text { Learners (students, listeners) in the } \\
\text { digital educational ecosystem }\end{array}$ & 10 \\
\hline $\begin{array}{l}\text { Teachers (course and module } \\
\text { developers) on the educational } \\
\text { platform }\end{array}$ & 15 \\
\hline
\end{tabular}

From Table 2, it is obvious that in relation to the digital educational environment, a digital (technological) platform plays a special role, providing unlimited opportunities for the integrated work of all stakeholders participants in the digital network structure, as a result of whose joint work on a single platform, a synergistic effect is created that significantly increases the cost of an intellectual capital.

The most influential element (factor) of the digital educational ecosystem is the digital technological (educational) platform, the significance of which in the system of factors affecting intellectual capital is 30 points, and the least significant factor was the "learners" factor (10 points). The absence of at least one of the elements violates the principles of integrity and emergence. The factors noted in Table 2, according to the respondents, are the most significant in the process of ensuring the growth of the intellectual capital of the digital educational ecosystem. This is facilitated by the specificity of digital technologies that perform the functions: accumulation, storage, analysis, processing and transmission of knowledge to students.

The digital platform has a number of features: a) it breaks down geographic boundaries and limits the number of listeners; b) significantly reduces financial costs and eliminates the loss of time associated with the physical movement of both the teacher and the student (listener); c) allows the educational system to provide personalized educational services (for example, it makes it possible to choose a piece of program or discipline for study); d) provides students with unlimited access to library resources, sources and databases; e) "frees" the teacher from the routine process of continuous lecturing and reduces the workload, since there is a possibility of a one-time recording of a lecture and its replication using information and communication technologies. The lecturer has free time for other types of scientific and pedagogical activities.

\section{Conclusion}

The digital educational ecosystem should be formed on the basis of trends in the development of the world educational space and taking into account the characteristics of the modern intellectual economy. This process should proceed in the following directions:

1) the creation of a personalized educational environment (human - IT), the creation of unique (personal) educational technologies and trajectories.

2) the development of global educational platforms (the so-called "universities per million students").

3 ) the formation of a collective educational environment (person-person), communities of practice that provide support or mentoring.

4) creation of a local educational environment, which is a local ecosystem of lifelong education.

5) creation of an environment for self-education of students at any time and in any place.

The main principles of the digital education ecosystem should be:

1) consistency and complexity, designed to ensure interdisciplinarity and multidisciplinarity in teaching. The approach to teaching involves the development of disciplines that are different in their content, that is, from different angles. With this approach, each participating discipline does not lose its identity, but on the contrary 
complements the others; the ability to build connections between phenomena is formed to manage all types of resources in a complex manner.

2) holism, which underlies the transdisciplinary approach to learning. This approach presupposes learning "through", "across" the boundaries of many disciplines, when at the junction of sciences new sciences and disciplines appear, new professions appear that did not exist before. Ecosystem education built on digital technologies is focused on the development of emotional intelligence, first of all, communication skills, the ability to work in a team, the ability to listen to others, analyze the situation and make a compromise.

3) rationalism, implying learning based on the development of cognitive abilities, the ability to perceive and analyze a large amount of information, the ability to work with a large amount of content, skills in solving complex problems.

4) pragmatism, focused on the development of the ability to assess possible and / or missed benefits, including economic, social, technological, etc. The pragmatic approach is focused on the development of skills to design, evaluate results, and adequately assess their capabilities.

The exponential development of the modern intellectual economy (that is, the intensive growth of the intellectual capital of the modern economy) depends on the intellectual intensity of the educational environment, its readiness to use knowledge-intensive techniques and technologies in teaching. This situation obliges modern society to move on to building a new model of education, which relies on the use of digital technology platforms that provide unlimited access to information sources and digital content and contribute to the intensive development of intellectual capital as the main resource for economic development. In conclusion, it can be noted that the new view substantiated the objective expediency of revising the structure and content of the traditional education system and the inevitability of its consistent and systemic digitalization, built on the principles of inter- and trans-disciplinary approaches to learning.

\section{References}

1. A.G. Tansley, J. Ecology. 16(3), 284 (1935)

2. Ecosystem, Retrieved from: https://ru.wikipedia.org/wiki/

3. J. Moor, J. Harvard Business Review. May-June. 75 (1993)

4. A. Katrich, Digital financial ecosystems Retrieved from: https://asros.ru/upload/iblock/4c5/19421_katrich. pdf

5. R. Isaev, Banking ecosystems will capture many industries in the economy in the coming years Retrieved from: https://www.businessstudio.ru/articles/article/ban kovskie_ekosistemy_zakhvatyat_mnogie_otrasli_ isaev/
6. D.O. Koroleva, T.O. Naushirvanov, J. Facts of Education. 6(31), (2020)

7. O.S. Kolesnikova, I.N. Molchanov, S.Y. Simonov, J. Tekhnologiya textile industry. 4(370), (2017)

8. V.V. Ivanova, Current problems of economics and management 190-193 (2017)

9. S.G. Grigoriev, R.A. Sabitov, G.S. Smirnova, Sh.R. Sabitov, Computer science and Education 5, 15-23, (2020) https://doi.org/10.32517/02340453-2020-35-5-15-23

10. S.N. Gavrilov, S.I. Volodina, J. Actual problems of Russian law. 6(103), 156-166 (2019)

11. N. Zakharov, I. Britvina, A. Kuznetsov, The impact of industry 4.0 on job creation, 457-462, (2020)

12. K. Schwab, N. Davis, Technologies of the Fourth Industrial Revolution, 320, (2018)

13. F. Nachira, P. Dini, Network of Digital Business Ecosystems for Europe: Roots, Processes and Perspectives. (2007)

14. B. Talin, What is a digital ecosystem? Retrieved from: https://morethandigital.info/ru/chto-takoyetzifrovaya-ekosistyema-ponimaniye-naibolyeyeviguodnoy-biznyes-modyeli/

15. Markelov M., Digital ecosystem: what it is, features of its perception and typical mistakes URL: https://vc.ru/future/70143-cifrovayaekosistema-chto-eto-takoe-osobennosti-eevospriyatiya-i-tipichnye-oshibki

16. A. Tsvetkova, M. Gustafsson, J. Clean. Prod., 246-254, (2012)

17. M.A. Kondakov, Ecosystem of digital education Retrieved from: https://firo.ranepa.ru/files/docs/cifr_didactika/ple nar/kondakov_plenar.pdf

18. About the university 20.35. URL: https://2035.university/about/

19. Pandemic of digital education. URL: https://vc.ru/ education/153144-pandemiya-cifrovogoobrazovaniya

20. National project "Education". URL: https://edu. gov.ru/national-project/projects/cos/

21. Ministry of Digital Development, Communications and Mass Media of the Russian Federation "Digital Economy of the Russian Federation". URL: https://digital.gov.ru/ru/

22. A.E. Suleimankadieva, E.A. Tkachenko, M.A. Petrov, O.Y. Syrovatskaya, R.V. Klyarovskaya ICICKM 2020. 346-353, (2020) https://doi.org/10.34190/IKM.20.061 